\title{
Bricks or clicks? Predicting student intentions in a blended learning buffet
}

\author{
Michelle Hood \\ Griffith Health Institute and School of Applied Psychology, Griffith University
}

\begin{abstract}
This study examined predictors of students' intentions to access face-to-face (f2f) or online options for lectures and tutorials in a buffet-style blended learning 2nd-year psychology statistics course $(N=113 ; 84 \%$ female). Students were aged 18 to 51 years $(M=23.16 ; S D$ $=6.80)$. Practical and technological predictors, along with attitudinal and motivational factors drawn from the expectancy value model, were tested. Higher work commitments, greater reliance on rehearsal, higher self-regulation, and higher critical thinking were the most important predictors of intentions to use online lectures. Almost $40 \%$ of the variance in those intentions was explained. Having the required computer software was the only independent predictor of intentions to attend synchronous online tutorials. Overall, $10 \%$ of the variance in those intentions was explained. Intentions to access asynchronous (archived) online tutorials were uniquely predicted by lower ability and higher extrinsic motivation. Overall, $26 \%$ of the variance in those intentions was explained. The predictors did not explain significant variance in intentions to attend $\mathrm{f} 2 \mathrm{f}$ lectures or tutorials. These findings contribute to understanding how students go about making choices when faced with buffet style blended learning courses. Motivational and practical factors both influence the choices students make.
\end{abstract}

\section{Introduction}

When blended learning is well understood and implemented, higher education will be transformed in a way not seen since the expansion of higher education in the late 1940s (Garrison \& Vaughan, 2008, p. 10)

Blended learning refers to integrating technology or media with traditional face-to-face (f2f) learning activities in a planned and pedagogically sound manner (Picciano, 2009). Bleed (2001) called this a "mix of bricks and clicks" (p. 24). Blended learning produces greater student engagement, achievement, and satisfaction than traditional or purely online approaches, although there are mixed results (Chen, Lambert, \& Guidry, 2010; Means, Toyama, Murphy, Bakia, \& Jones, 2009). The mixed results may arise from the wide range of approaches to blended learning currently employed and the lack of understanding about how student characteristics influence what works best for a given individual.

Twigg (2003) described five broad approaches to blended learning. These range from the supplemental approach, in which online activities supplement the largely unchanged traditional $\mathrm{f} 2 \mathrm{f}$ teaching, to fully online approaches, in which online activities replace all $\mathrm{f} 2 \mathrm{f}$ activities. The buffet approach offers students a choice of options customised to their background, learning preferences, and goals. This approach does not treat students as if they were all the same and would all prefer and benefit from the one predetermined way of learning. The current study examined how individual differences influence student intentions to access online versus f $2 \mathrm{f}$ options in a buffet-style blended learning statistics course.

Most of the published research on what format students choose in buffet-style courses has focused on practical and technological predictors. Williams and Fardon (2007) reported that Australian university students chose recorded over f2f lectures because of timetable clashes (47\%) and outside commitments (43\%). Matheos, Daniel, and McCalla (2005) found that having internet connectivity at home was associated with higher access of online resources in a buffet-style computer science course. Learning style was also important. Independent learners preferred technology-based support, whereas collaborative learners preferred $\mathrm{f} 2 \mathrm{f}$ interaction. Huang, Lin, and Huang (2011) also found that learning style affected online participation in a blended learning software usage course. Having a higher sensory learning style was associated with greater online participation. Sensory learners are more practical and prefer learning facts and solving problems via well-established methods. Students' study skills and learning styles are initially assessed to inform their choices from the buffet offered in Ohio State University's introductory 
statistics courses (Program in Course Redesign, 2005); however, published details on the relationships between these factors and the choices made are not available.

Studies that have examined student choices between fully online or fully f $2 \mathrm{f}$ formats have also identified predictors that might apply to choices made in a buffet-style blended course. Rose, Frisby, Hamlin, and Jones (2000) found that practical considerations (distance to campus and competing time commitments) and attitudinal/motivational factors (desire for a new challenge and lower self-efficacy for the course) predicted choice of the online option in a graduate nursing epidemiology course. By comparison, not owning a computer, low computer self-efficacy, and preference for $\mathrm{f} 2 \mathrm{f}$ discussion and interaction predicted the f2f choice. Artino (2010) found that higher self-efficacy for learning online and lower value for the task predicted stronger preference for fully online delivery of an aviation course. Thus, student motivational beliefs are important in determining their choices.

Several studies have used the technology acceptance model (TAM, Davis, Bagozzi \&Warshaw, 1989) to understand how perceptions and attitudes influence students' or workers' behavioural intentions to engage in online learning (e.g., Chang \& Tung, 2008; Cheng, 2011; Tselios, Daskalakis, \& Papadopoulou, 2011). Perceptions of usefulness, ease of use of the online activities, and system quality, along with computer self-efficacy, predict behavioural intentions, although results are mixed (see Tselios et al., 2011). Cheng (2011) extended this model to show that intrinsic motivation predicted perceived enjoyment of online learning, which, in turn, predicted intentions to engage with it. Behavioural intentions strongly predict actual usage, which, in turn, strongly predicts perceived performance (Cheng, 2011).

TAM developed from the expectancy value model (EVM, Fishbein \& Ajzen, 1975). According to the EVM, behaviour and behavioural intentions are functions of expectancies (beliefs) that particular outcomes will result and values (affective evaluations) associated with those outcomes (Palmgreen, 1984). When confronted with a choice of behaviours, the option that provides the greatest outcomes in terms of combined expectancies and values is chosen. Many studies focus on behavioural intentions, because intentions are the strongest predictors of behaviours (Ajzen, 2002). The current study used Eccles's broader EVM of achievement (e.g., Eccles, 2005; Eccles et al., 1983), which incorporates demographic factors, past experiences, affective reactions, and goals, as well as values and expectancies, as predictors of achievement-related behaviours. The aim was to explain student intentions to use online or $\mathrm{f} 2 \mathrm{f}$ options in a blended learning buffet that was offered in a 2nd-year compulsory research methods and statistics course in an Australian undergraduate psychology degree.

The existing research on blended learning approaches in statistics teaching has generally described the approaches used and/or reported their effectiveness on student satisfaction, engagement, or performance (e.g., Baharun \& Porter, 2009; Neumann \& Hood, 2009; Neumann, Neumann, \& Hood, 2011; Schober, Wagner, Reimann, Atria, \& Spiel, 2006; Tudor, 2006; Utts, Sommer, Acredolo, Maher, \& Matthews, 2003; Ward, 2004; Yablon \& Katz, 2001). However, Utts et al. (2003) examined predictors of student choice of a blended learning or $\mathrm{f} 2 \mathrm{f}$ version of the same introductory statistics course. They found similar practical (timetabling) and technological (desire to improve computer skills) predictors to those identified by Rose et al. (2000) in graduate nursing students. There was some evidence that lower value (course not a part of their major) and a deeper approach to learning (belief that it would expand their knowledge and critical/analytic skills) predicted the blended learning choice. However, to date no studies have examined student choices in a buffet-style blended learning course.

\section{Statement of the problem}

To date, little research has been conducted on factors that influence whether students intend to choose f $2 \mathrm{f}$ versus online options in a buffet-style blended learning environment, especially in statistics courses. This knowledge will enable educators to better tailor blends to student characteristics. In the current study, students were offered access to lectures f2f or asynchronously via recordings available to download or stream. Similarly, tutorials could be attended $\mathrm{f} 2 \mathrm{f}$, virtually in real-time (synchronous), or via archived recordings (asynchronous) available to download or stream. The study extended on previous research which has mainly examined practical and technological predictors by also examining attitudinal and motivational factors drawn from the EVM. Practical and technological predictors were outside commitments (work, family), Internet and software resources, and distance to campus. Attitudinal and motivational predictors based on the EVM were values (e.g., attitudes toward statistics), affective 
reactions (statistics anxiety), expectancies (statistics and learning self-efficacy), extrinsic and intrinsic motivation, learning strategies, and ability (past statistics performance). The main research questions were whether these practical, technological, attitudinal, and motivational factors would predict student intentions to use either $\mathrm{f} 2 \mathrm{f}$ or online access, and, if so, what were the most important predictors of each mode of delivery.

\section{Method}

The author's university ethics committee approved this study. Participation in completing the pen-andpaper questionnaire in the first lecture of the course was voluntary. Selection of attendance method was also voluntary.

\section{Description of the course}

This is a compulsory course for students enrolled in the 2nd year of psychology degrees and is the third compulsory research methods and statistics course in their degree. This course teaches experimental and correlational research design and analysis. Conceptual and theoretical content is covered in lectures. In tutorials, students gain practical experience in designing studies, conducting and interpreting analyses using Statistics Package for the Social Sciences (SPSS (C), and report writing skills (American Psychological Association [APA], 2009). Assessment consists of mid-semester and final exams and an APA style (2009) research report based on original data collected in the course.

\section{Description of the buffet-style blended learning approach}

Students had choices of both online and f2f options for the weekly lectures and tutorials. Face-to-face lectures (delivered by the author) were captured (audio of the instructor with visual of the PowerPoint presentation) using Lectopia (http:/www.lectopia.com.au/). Captured lectures were accessed via the Blackboard (http://www.blackboard.com/) learning and teaching system used for online course support. Students could stream audio only or audio-visual using Flash or QuickTime or could download audio only as an MP3 file or audio-visual for PC/laptop/iPod.

For tutorials, students could attend the $\mathrm{f} 2 \mathrm{f}$ version or synchronous or asynchronous virtual versions. The author used Wimba Classroom (http://www.wimba.com/products/wimba_classroom) to deliver a virtual tutorial. Wimba Classroom enables live audio (via microphone) and visual (of participants via webcams and of the presenter's desktop) communication in real-time. All activities and facilities possible in a $\mathrm{f} 2 \mathrm{f}$ classroom (e.g., projecting the presenters desktop to demonstrate analyses, using a whiteboard, having a student present, interaction, breakout groups) are replicated in the Wimba classroom. These synchronous virtual tutorials were also archived (captured and accessed in a similar fashion to the captured lectures), providing a third asynchronous online option for tutorials.

\section{Participants}

Participants were 113 undergraduate psychology students (15.9\% male, $84.1 \%$ female) enrolled in the participating course at a large urban university in Queensland, Australia. This represented 69.75\% of students in the course. Mean age was 23.16 years $(S D=6.80$; range $=18-51 ; 2$ participants did not report age). Most were domestic students (96.5\%). Therefore, English was the main language for $92.9 \%$ of the participants. Most participants were enrolled in a single psychology degree $(92.9 \%)$, with the remainder enrolled in double degrees with psychology and law $(2.7 \%)$, exercise science $(0.9 \%)$, human resource management $(2.7 \%)$, and criminology $(0.9 \%)$. The majority were full-time students, completing three $(22.1 \%)$, four $(65.5 \%)$, or five courses $(4.5 \%)$. The remainder were part-time, completing one $(4.5 \%)$ or two courses $(2.7 \%)$. A few $(7.1 \%)$ were repeating the course because they had previously failed it $(3.55 \%)$ or to improve their grade $(3.55 \%)$.

Only six participants reported not having internet connectivity at home. Of those with internet access, only three participants reported dial-up access, with the remainder having broadband or satellite access (10 participants did not answer this). The SPSS software was available at home for $34.5 \%$ of the participants (one did not answer this). 


\section{Measures}

Participants reported age, gender, student status (domestic/international), main language, degree program, enrolment load, whether they were repeating the course, distance to campus, and outside commitments (work/volunteer or caring). They also reported their grades (from fail $=2$ to high distinction $=7$ ) in the two prerequisite research methods and statistics courses. Questions also asked about their internet connectivity at home (and, if so, what sort) and availability of SPSS (essential in the tutorials).

Participants indicated their intentions to access the online and $\mathrm{f} 2 \mathrm{f}$ options available in the course using a visual analogue scale, anchored by never (1) and weekly (10) with the midpoint indicated as about half the semester (5). They also completed measures of statistics attitudes, anxiety, and self-efficacy, motivation, and learning strategies.

The Statistics Anxiety Rating scale (STARS; Cruise \& Wilkins, 1980) is a 51-item scale that assesses statistics anxiety and attitudes. The wording of some items was modified to reflect the Australian context (e.g., "professor" was changed to "lecturer"). On the first 23 items, students rate how anxious they feel in statistical situations, using a 5-point Likert scale from $1=$ no anxiety to $5=$ considerable anxiety. This yields three composite subscale scores; test and class anxiety ( 8 items; e.g., "Studying for an examination in a statistics course"), interpretation anxiety (11 items; e.g., "Trying to understand the odds in a lottery"), and fear of asking for help (4 items; e.g., "Asking someone in the computer lab for help in understanding statistical output on the computer"). On the remaining 28 items, students rate attitudes toward statistics using a 5-point scale from $1=$ strongly disagree to $5=$ strongly agree. This also yields three composite subscale scores: worth of statistics (16 items; e.g., "I feel statistics is a waste"), fear of statistics teachers (5 items; "Statistics teachers are so abstract they seem inhuman"), and computational self-concept (7 items; "I am too slow in my thinking to get through statistics"). Total subscale scores were formed by summing the relevant items and averaging (maximum score $=5$ ). Higher scores indicate higher anxiety or attitudes that are more negative (i.e., statistics as being worthless, high fear of statistics teachers, and poor computational self-concept). Hanna, Shevlin, \& Dempster (2008) confirmed the 6-factor structure. There is adequate validity and subscale internal reliabilities ranging from .64 to .94 (Baloglu, 2002; Hanna et al., 2008). The current sample yielded high internal reliabilities (Cronbach's $\alpha s)$; test/class anxiety (.86), interpretation anxiety (.88), fear of asking for help (.91), worth (.94), fear of statistics teachers (.76), and computational self-concept (.88).

The Statistics Self-Efficacy scale (Bandalos, Finney, \& Geske, 2003) is a 10-item scale that assesses selfperceptions of competence in statistics using a 7-point Likert response scale with anchors of $1=$ strongly disagree and 7 = strongly agree. The wording of some items was modified for the current context (e.g., "I think I am naturally good at statistics" reworded as "I think I am naturally good at research methods and statistics"). A total statistics self-efficacy score was computed by adding scores on all 10 items and calculating an average (maximum score $=7$ ). Higher scores indicate higher statistics self-efficacy. Bandalos et al. (2003) reported high internal reliability (Cronbach's $\alpha=.95$ ). The current data yielded an $\alpha$ of .94.

The 81-item Motivated Strategies for Learning Questionnaire (Pintrich, Smith, Garcia, \& McKeachie, 1991) assesses motivation (goals \& values, beliefs about skill to succeed, test anxiety) and learning strategies (cognitive \& metacognitive strategies, management of resources). Responses are made on a 7point scale from $1=$ not at all true of me to $7=$ very true of me. In total, there are 15 subscales. For each, items were summed and averaged (maximum score $=7$ ). There are six motivation subscales. Intrinsic goal orientation (4 items) assesses motivations of challenge, mastery, or curiosity. Extrinsic goal orientation (4 items) assesses motivations to gain grades or other rewards and to perform better than others do. Task value (6 items) assesses interest, importance, or usefulness attached to the course. Control of learning beliefs ( 4 items) assesses beliefs about outcome expectancies based on effort. Self-efficacy for learning and performance ( 8 items) assesses two aspects of expectancy: expectancy for success and selfefficacy for task performance. Test anxiety (5 items) assesses cognitive and affective components of worry related to the course. Pintrich et al. (1991) reported evidence for this 6-factor structure and Cronbach's $\alpha$ s that ranged from .62 to .93. The Cronbach's $\alpha$ s for the current sample were .59 (intrinsic motivation), .63 (extrinsic motivation), .83 (task value), .76 (control of learning beliefs), 95 (self-efficacy for learning and performance), and .77 (test anxiety). 
There are nine learning strategies subscales. Rehearsal (4 items), elaboration (6 items), and organization (4 items) assess memory and learning strategies that reflect increasingly deeper processing. Critical thinking (5 items) assesses critical application of previous knowledge to current learning tasks. Metacognitive self-regulation (12 items) assesses planning (goal setting), monitoring (tracking), and regulating (adjusting) learning. Time and study environment ( 8 items) assesses time management and suitability of study environment. Effort regulation (4 items) assesses ability to self-manage study goals in the face of difficulties or distractions. Peer learning (3 items) assesses collaboration and communication with peers to gain clarification and understanding not likely on one's own. Help-seeking (4 items) assesses support-seeking strategies when assistance is needed. Pintrich et al. (1991) reported evidence for this factor structure and Cronbach's $\alpha$ s that ranging from .52 to .80 . The Cronbach's $\alpha$ s for the current sample were .69 (rehearsal), .76 (elaboration), .65 (organization), .79 (critical thinking), .81 (metacognitive self-regulation), .82 (time \& study environment), .74 (effort regulation), .68 (peer learning), and .61 (help seeking).

\section{Results}

Data were initially screened for missing values and assumptions of the analyses. Six cases had missing values, which represented $0.85 \%$ missing values. Little's Missing Completely at Random Test indicated this was missing completely at random, $\chi^{2}(2480, N=113)=127.10, p=1.00$. As there was very little missing data, it was not replaced.

Descriptive statistics are in Table 1. The assumption of normality was violated for several variables. There was negative skew in self-efficacy for learning and performance (std. statistic $=-2.90$ ), learning beliefs (std. statistic $=-3.43$ ), extrinsic motivation (std. statistic $=-3.88$ ), number of courses enrolled in (std. statistic $=-7.28)$, intended attendance at $\mathrm{f} 2 \mathrm{f}$ tutorials ( $\mathrm{std}$. statistic $=-13.95)$, and intended attendance at $\mathrm{f} 2 \mathrm{f}$ lectures (std. statistic $=-14.64)$. There was some positive skew in intended attendance at virtual tutorials (std. statistic $=4.34)$, age $($ std. statistic $=10.57)$, and distance from campus (std. statistic $=$ 43.51). The skew in distance was largely due to one student who lived almost $900 \mathrm{~km}$ from campus and who flew in and out each week for class. This score was replaced by the next highest distance +1 (101 $\mathrm{km})$, which reduced the skew substantially $($ std. statistic $=8.35)$ while retaining the order of scores. Transformations were applied to normalise these skewed distributions, with reflections first applied to negatively skewed distributions. Inverse transformation improved but did not entirely normalise the distribution of age (std. statistic $=-5.82$ ), but normalised intended attendance at $\mathrm{f} 2 \mathrm{f}$ tutorials and lectures. Log transformations normalised the distributions of distance from campus, number of courses enrolled in, extrinsic motivation, self-efficacy for learning and performance, and learning beliefs. Square root transformation normalised the distribution of intended attendance at virtual tutorials. All other variables were normally distributed. Analyses were conducted using these transformed variables; however, for ease of interpretation, descriptive statistics are reported using untransformed values.

Initial univariate analyses were used to determine which of the practical, technological, demographic, and attitudinal/motivation variables were associated with intentions to access the different learning options. Those predictors that demonstrated significant univariate associations were then entered into a multiple regression analysis to determine how much variance in total they explained in the outcome (intention) and which variables made significant unique contributions.

Bivariate correlations are given in Table 2. There were significant correlations between the intended modes of accessing content. Greater intention to attend $\mathrm{f} 2 \mathrm{f}$ tutorials was strongly associated with greater intention to attend $\mathrm{f} 2 \mathrm{f}$ lectures, indicating a consistent preference for $\mathrm{f} 2 \mathrm{f}$ learning. Similarly, there was a strong positive correlation between intention to access tutorial and lecture material online. Greater intention to access $\mathrm{f} 2 \mathrm{f}$ tutorials was associated with lower intention to attend virtual tutorials, indicating that there was a tendency to choose one form of access over the other.

Age, main language, student status, enrolment load, repeating the course, program of study, family or carer responsibilities, and distance from campus were not significantly associated with any intentions so were not included in subsequent regression analyses. There were no effects of internet connectivity or type of connectivity at home. This was most likely due to only six students not having internet access at home and only three reporting dial-up rather than broadband access. No variables were significantly associated with intentions to attend $\mathrm{f} 2 \mathrm{f}$ tutorials, so no further results are presented for that outcome. 
Table 1

Descriptive statistics for demographic details, STARS, statistics self-efficacy, MSLQ, and intentions

\begin{tabular}{|c|c|c|}
\hline Variable & $M(95 \% C I)$ & Range \\
\hline Age (years) & $23.16(21.88 ; 24.45)$ & $18-51$ \\
\hline Grade 1 st year ${ }^{a}$ & $5.10(4.93 ; 5.27)$ & $4-7$ \\
\hline Grade 2 nd year ${ }^{a}$ & $5.43(5.22 ; 5.64)$ & $4-7$ \\
\hline Enrolment Load (courses) & $3.63(3.48 ; 3.78)$ & $1-5$ \\
\hline Hours work/volunteer per week & $13.35(11.48 ; 15.22)$ & $0-40$ \\
\hline Distance from campus (kms) & $20.05(15.96 ; 24.14)$ & $0.5-101^{b}$ \\
\hline \multicolumn{3}{|l|}{$\operatorname{STARS}(\max =5)$} \\
\hline Test/class Anxiety & $2.93(2.78 ; 3.08)$ & $1.13-4.63$ \\
\hline Interpretation Anxiety & $2.40(2.27 ; 2.53)$ & $1.09-3.91$ \\
\hline Help-seeking Anxiety & $2.33(2.14 ; 2.52)$ & $1.00-4.75$ \\
\hline Worth & $2.08(1.93 ; 2.22)$ & $1.00-4.25$ \\
\hline Fear Statistics Teachers & $1.81(1.69 ; 1.94)$ & $1.00-3.60$ \\
\hline Computational Self-Concept & $2.07(1.92 ; 2.23)$ & $1.00-4.43$ \\
\hline Statistics Self-Efficacy $(\max =7)$ & $4.45(4.26 ; 4.65)$ & $1.30-6.90$ \\
\hline \multicolumn{3}{|l|}{$\operatorname{MSLQ}(\max =7)$} \\
\hline Intrinsic Motivation & $4.77(4.60 ; 4.94)$ & $2.25-7.00$ \\
\hline Extrinsic Motivation & $5.52(5.33 ; 5.71)$ & $1.50-7.00$ \\
\hline Task Value & $5.09(4.92 ; 5.27)$ & $2.50-7.00$ \\
\hline Control Learning Beliefs & $5.84(5.68 ; 6.00)$ & $2.75-7.00$ \\
\hline SE for learning and performance & $4.90(4.71 ; 5.10)$ & $2.25-7.00$ \\
\hline Test Anxiety & $4.01(3.77 ; 4.25)$ & $1.00-6.60$ \\
\hline Rehearsal & $4.87(4.66 ; 5.08)$ & $1.75-7.00$ \\
\hline Elaboration & $5.07(4.89 ; 5.26)$ & $3.00-7.00$ \\
\hline Organization & $5.08(4.89 ; 5.28)$ & $2.25-7.00$ \\
\hline Critical Thinking & $4.04(3.82 ; 4.26)$ & $1.00-7.00$ \\
\hline Self-regulation metacognition & $4.56(4.40 ; 4.72)$ & $1.83-6.58$ \\
\hline Self-regulation time and study environment & $5.04(4.84 ; 5.24)$ & $2.25-7.00$ \\
\hline Self-regulation Effort & $5.01(4.80 ; 5.21)$ & $2.25-7.00$ \\
\hline Peer Learning & $4.63(4.38 ; 4.89)$ & $1.00-7.00$ \\
\hline Help-Seeking & $4.28(4.05 ; 4.51)$ & $1.00-6.75$ \\
\hline \multicolumn{3}{|l|}{ Intentions $(\max =10)$} \\
\hline F2F lecture & $8.95(8.67 ; 9.24)$ & $1.2-10$ \\
\hline Lecture Capture & $5.75(5.19 ; 6.31)$ & $0.2-10$ \\
\hline F2F Tutorial & $8.87(8.56 ; 9.18)$ & $1-10$ \\
\hline Virtual Tutorial & $3.06(2.55 ; 3.57)$ & $0-10$ \\
\hline Archived Tutorial & $4.89(4.36 ; 5.41)$ & $0-10$ \\
\hline
\end{tabular}

${ }^{a}$ Pass $=4$, High Distinction $=7$ (students required pass in order to proceed into this course)

${ }^{\mathrm{b}}$ Extreme high score of 887 replaced with $101(=$ next highest score +1$)$ 
Table 2 Bivariate correlations

\begin{tabular}{|c|c|c|c|c|c|c|c|c|c|c|c|c|c|c|c|c|c|c|c|c|c|c|c|c|}
\hline Var & iable & 1 & 2 & 3 & 4 & 5 & 6 & 7 & 8 & 9 & 10 & 11 & 12 & 13 & 14 & 15 & 16 & 17 & 18 & 19 & 20 & 21 & 22 & 23 \\
\hline 1 & Grade 1st yr & - & & & & & & & & & & & & & & & & & & & & & & \\
\hline 2 & Work & $-22 *$ & - & & & & & & & & & & & & & & & & & & & & & \\
\hline 3 & Test/class Anx & $-47 *$ & 10 & - & & & & & & & & & & & & & & & & & & & & \\
\hline 4 & Interpret Anx & $-34 *$ & -01 & $68 *$ & - & & & & & & & & & & & & & & & & & & & \\
\hline 5 & Worth & $-43 *$ & 18 & $48^{*}$ & $35^{*}$ & - & & & & & & & & & & & & & & & & & & \\
\hline 6 & Fear Teach & $-29 *$ & 08 & $40^{*}$ & $29^{*}$ & $72 *$ & - & & & & & & & & & & & & & & & & & \\
\hline 7 & Comput SC & $-40^{*}$ & 16 & $58^{*}$ & $42 *$ & $74 *$ & $60^{*}$ & - & & & & & & & & & & & & & & & & \\
\hline 8 & Statistics SE & $47^{*}$ & $22 *$ & $-61^{*}$ & $-48^{*}$ & $-60 *$ & $-43 *$ & $-64 *$ & - & & & & & & & & & & & & & & & \\
\hline 9 & Extrin Motiv & -02 & 01 & -15 & -04 & 17 & 11 & 13 & $-20 *$ & - & & & & & & & & & & & & & & \\
\hline 10 & Task Value & $37 *$ & -11 & $-20 *$ & $-19^{*}$ & $-71 *$ & $-47 *$ & $-52 *$ & $49 *$ & $-32 *$ & - & & & & & & & & & & & & & \\
\hline 11 & Rehearsal & -02 & -07 & 13 & 09 & -15 & -09 & -07 & $20 *$ & -13 & $23^{*}$ & - & & & & & & & & & & & & \\
\hline 12 & Elaboration & $23 *$ & -07 & 02 & -04 & $41 *$ & $-34 *$ & $-21^{*}$ & $32 *$ & $-35^{*}$ & $55^{*}$ & $55^{*}$ & - & & & & & & & & & & & \\
\hline 13 & Organization & 06 & -06 & $19^{*}$ & -02 & -12 & $-21^{*}$ & -01 & 10 & $-39 *$ & $29 *$ & $49 *$ & $66^{*}$ & - & & & & & & & & & & \\
\hline 14 & Critical Think & 03 & 00 & 07 & -07 & $-28^{*}$ & -15 & -10 & $19 *$ & -12 & $44^{*}$ & $28^{*}$ & $59 *$ & $38^{*}$ & - & & & & & & & & & \\
\hline 15 & Metacognition & $25^{*}$ & -14 & -10 & -11 & $-45^{*}$ & -34 & -23 & $42 *$ & $-29 *$ & $50 *$ & $57 *$ & $79 *$ & $54 *$ & $55^{*}$ & - & & & & & & & & \\
\hline 16 & Environ & $22 *$ & $-22 *$ & -10 & -10 & -37 & $-35^{*}$ & -12 & $28^{*}$ & $-22 *$ & $38^{*}$ & $39 *$ & $60 *$ & $49^{*}$ & $29^{*}$ & $70^{*}$ & - & & & & & & & \\
\hline 17 & Self-reg Effort & $22 *$ & $-20 *$ & $-21^{*}$ & -14 & $-44 *$ & $-34 *$ & $-25^{*}$ & $37^{*}$ & -15 & $43^{*}$ & $30 *$ & $52 *$ & $34 *$ & $23 *$ & $63 *$ & $79 *$ & - & & & & & & \\
\hline 18 & Peer Learning & $37 *$ & -09 & 09 & -01 & -16 & -12 & $-21^{*}$ & 18 & -14 & $25^{*}$ & $42 *$ & $44^{*}$ & $36^{*}$ & $32 *$ & $29 *$ & 17 & 15 & - & & & & & \\
\hline 19 & F2F Lecture & $19 *$ & -10 & -09 & -13 & $-28 *$ & $-22 *$ & $-21^{*}$ & $21^{*}$ & -13 & 17 & 10 & 11 & 05 & 04 & 03 & 10 & 08 & 14 & - & & & & \\
\hline 20 & Lect Capture & $-20^{*}$ & $24 *$ & $20 *$ & 08 & -01 & 04 & 09 & -03 & $-30 *$ & 17 & $28 *$ & $33 *$ & $35^{*}$ & $25^{*}$ & $20 *$ & $29 *$ & $23 *$ & 15 & -03 & - & & & \\
\hline 21 & F2F Tute & 16 & 00 & -01 & -01 & -18 & -17 & -12 & 15 & -18 & 13 & -03 & 02 & -01 & -08 & 00 & 11 & 03 & -04 & $72 *$ & -02 & - & & \\
\hline 22 & Virtual Tute & -08 & 01 & 05 & 06 & 03 & 14 & 12 & -12 & -07 & 06 & 15 & 14 & 15 & $21^{*}$ & 05 & -02 & -09 & $23^{*}$ & -16 & $29 *$ & $-30 *$ & - & \\
\hline 23 & Archive Tute & $-24 *$ & 06 & 15 & $22 *$ & -01 & 08 & 17 & -06 & $-33^{*}$ & 10 & $25^{*}$ & $19^{*}$ & $22 *$ & 16 & 13 & $21^{*}$ & 15 & 10 & 01 & $66^{*}$ & -01 & $39^{*}$ & - \\
\hline
\end{tabular}

Note. Only those predictors significantly correlated with intentions were included 


\section{Predictors of intention to attend f2f lectures}

Lower grades in previous statistics courses, lower statistics self-efficacy, lower computational selfcompetence, lower worth of statistics, and greater fear of statistics teachers were associated with lower intentions to attend $\mathrm{f} 2 \mathrm{f}$ lectures. Thus, poorer perceptions of statistics ability along with evidence of poorer past performance and more negative attitudes about statistics and statistics teachers were associated with intentions to avoid attending lectures $\mathrm{f} 2 \mathrm{f}$.

To determine the unique contributions of these predictors to explaining variance in intentions to attend $\mathrm{f} 2 \mathrm{f}$ lectures, they were entered into a standard multiple regression analysis (see Table $3 \mathrm{a}$ ). They just failed to account for a significant percentage of variance $\left(R^{2}=.09, R_{\text {adj }}^{2}=.05\right), p=.08$. When entered together, no individual predictor made a significant unique contribution.

Table 3

Predicting intention to access lectures face-to-face ( $f 2 f)$ or online (captured lecture)

\begin{tabular}{|c|c|c|c|c|}
\hline Variables & $B$ & $S E(B)$ & $\beta$ & $p$ \\
\hline \multicolumn{5}{|c|}{ a) $\quad$ Criterion $=\mathrm{f} 2 \mathrm{f}$ Lecture (reflected and inverse transformed) } \\
\hline Grade 1st Year & 0.04 & 0.03 & .15 & .210 \\
\hline Statistics Self Efficacy & 0.00 & 0.03 & -.01 & .938 \\
\hline Worth & -0.08 & 0.06 & -.27 & .144 \\
\hline Computational SC & 0.01 & 0.05 & .04 & .777 \\
\hline Fear Statistics Teachers & 0.01 & 0.05 & .02 & .903 \\
\hline \multicolumn{5}{|c|}{$R^{2}=.09, F(5,93)=2.04, p=.08$} \\
\hline \multicolumn{5}{|c|}{ b) Criterion = Captured Lecture } \\
\hline Work Hrs & 0.08 & 0.03 & .27 & $.002 *$ \\
\hline Grade 1st Year & -0.48 & 0.33 & -.14 & .158 \\
\hline Class/test Anxiety & 0.08 & 0.35 & .02 & .821 \\
\hline Extrinsic Motivation (reflect, log transformed) & -2.83 & 1.48 & -.18 & .058 \\
\hline Rehearsal & 0.96 & 0.31 & .36 & $.002 *$ \\
\hline Elaboration & 0.11 & 0.48 & .04 & .819 \\
\hline Organisation & 0.21 & 0.34 & .07 & .542 \\
\hline Self-regulation Time and Study Environment & 0.95 & 0.44 & .35 & $.031 *$ \\
\hline Self-regulation Metacognition & -1.57 & 0.57 & -.46 & $.007 *$ \\
\hline Self-regulation Effort & 0.05 & 0.40 & .02 & .894 \\
\hline Critical Thinking & 0.63 & 0.27 & .25 & $.022 *$ \\
\hline \multicolumn{5}{|c|}{$R^{2}=.39, F(11,91)=5.37, p<.001$} \\
\hline
\end{tabular}

\section{Predictors of intention to access captured lectures}

Number of hours of work/volunteering per week was positively correlated with intention to use lecture capture. Thus, the more hours worked, the greater the intention to access lecture material online. Lower past performance in statistics; higher statistics test/class anxiety; greater extrinsic motivation; greater use of rehearsal, organisation, and elaboration strategies; greater self-regulation of metacognition, time and the study environment, and effort; and higher critical thinking were also associated with greater intentions to use the lecture capture. Thus, students who had lower ability, higher statistics anxiety, and who showed performance-oriented motivation reported stronger intentions to use the online lecture material. However, so did those students who were more self-regulated, had higher critical thinking, and engaged in more memorisation strategies to learn material.

Those significant univariate predictors were entered into a multiple regression analysis (see Table $3 b$ ). Together, these 11 predictors explained $39.3 \%$ (32\% adjusted) of the variance in intentions to use lecture capture, $F(11,91)=5.37, p<.001$. Several made significant independent contributions: hours of work $(6.66 \%)$, rehearsal $(6.5 \%)$, self-regulation of metacognitive strategies $(5.06 \%)$, critical thinking $(3.65 \%)$, and self-regulation of time and the study environment (3.20\%). Thus, work commitments and reliance on rehearsal were the strongest predictors of intentions to use lecture capture. The remaining variables no longer made significant independent contributions. 


\section{Predictors of intention to attend synchronous virtual tutorials}

Students who had SPSS on their home computer $(n=73)$ intended to attend more virtual tutorials $(M=$ $3.92, S E M=0.50)$ than those who did not $(n=38 ; M=2.61, S E M=0.28), t(109)=-2.23, p=.028, d=$ 0.47. This represents a small effect size according to Cohen (1988). Higher engagement in critical thinking and use of peer learning were also associated with greater intentions to attend the virtual tutorials. Thus, students who engaged in deeper processing of material and who recognised the importance of peer discussion and interaction to their learning, as well as those who had the technology required to do this at home, had stronger intentions to attend this tutorial option.

These three predictors (SPSS at home, critical thinking, and peer learning) were entered into a standard multiple regression analysis (see Table $4 \mathrm{a})$. Together, they explained a significant $10.4 \%$ (7.9\% adjusted) of the variance in intention to attend the virtual tutorials, $F(3,106)=4.11, p=.008$. Only SPSS made a significant unique contribution, explaining $3.96 \%$ of the variance in intentions to attend the virtual tutorials.

Table 4

Predicting intention to access synchronous (virtual) or asynchronous (archived) tutorials

\begin{tabular}{|c|c|c|c|c|}
\hline Variables & $B$ & $S E(B)$ & $\beta$ & $p$ \\
\hline \multicolumn{5}{|c|}{ a) Criterion $=$ Virtual Tutorial (square root transformed) } \\
\hline SPSS $^{a}$ & 0.34 & 0.16 & .20 & $.033 *$ \\
\hline Critical Thinking & 0.09 & 0.07 & .13 & .179 \\
\hline Peer Learning & 0.09 & 0.06 & .15 & .134 \\
\hline \multicolumn{5}{|c|}{$R^{2}=.10, F(3,106)=4.11, p=.008$} \\
\hline \multicolumn{5}{|c|}{ b) Criterion $=$ Archived Tutorials } \\
\hline Gender $^{b}$ & 0.95 & 0.74 & .13 & .202 \\
\hline Grade 1st Year & -0.63 & 0.32 & -.20 & $.048 *$ \\
\hline Interpretation Anxiety & 0.33 & 0.42 & .08 & .433 \\
\hline Extrinsic Motivation (reflect, log transformed) & -3.60 & 1.50 & -.24 & $.019 *$ \\
\hline Rehearsal & 0.48 & 0.27 & .20 & .077 \\
\hline Elaboration & -0.03 & 0.40 & -.01 & .949 \\
\hline Organisation & 0.00 & 0.34 & .00 & .993 \\
\hline Time and Study Environment & 0.25 & 0.30 & .10 & .415 \\
\hline \multicolumn{5}{|c|}{$R^{2}=.26, F(8,94)=4.12, p<.001$} \\
\hline
\end{tabular}

${ }^{\mathrm{a}} \mathrm{No}=0$, Yes $=1{ }^{\mathrm{b}}$ Male $=0$, Female $=1$

\section{Predictors of intention to access asynchronous virtual tutorials}

Female students intended to use the archived virtual tutorials more $(M=5.19, S E M=0.28)$ than did male students $(M=3.32, S E M=0.67), t(108)=-2.70, p=.008, d=0.68$. This represents a medium effect size according to Cohen (1988). Lower past performance in statistics; greater interpretation anxiety; higher extrinsic motivation; higher reliance on rehearsal, organisation, and elaboration strategies; and higher self-regulation of time and the study environment were associated with greater intentions to use the archived virtual tutorials. Thus, intentions to access the archived tutorials online were related to lower ability and anxiety over having to interpret statistical information, which is a large part of the tutorial activities, as well as with performance-oriented motivation. However, intentions to access these asynchronous online tutorials were also associated with greater use of memorisation learning strategies and self-regulation.

Together these eight predictors explained a significant $25.9 \%(19.6 \%$ adjusted $)$ of the variance in intentions to access the archived virtual tutorials, $F(8,94)=4.12, p<.001$ (Table $4 \mathrm{~b}$ ). There were significant independent contributions by 1 st year statistics grade, which explained $3.17 \%$ of the variance, and extrinsic motivation, which explained $4.54 \%$ of the variance. The remaining variance overlapped between all predictors. 


\section{Discussion}

Understanding how motivation and attitudes as well as practical and technological considerations affect student intentions to access different components in a blended learning buffet can help lecturers tailor the blend to students' needs. It is likely that a more tailored approach will lead, in turn, to better student engagement, achievement, and satisfaction. While blended learning courses offer integrated f $2 \mathrm{f}$ and online components, only buffet-style courses give students control over what mode of delivery they choose for a particular learning activity. Ideally, those choices are based on student background, learning styles, and goals (Twigg, 2003). However, to date, no studies had examined the factors associated with students' choices.

The current results demonstrate that motivation and attitudes are important predictors of student choices in a buffet-style blended learning course. While no predictors of intentions to attend f2f tutorials were identified, a cluster of negative attitudes, low motivation, and high anxiety predicted intentions to avoid $\mathrm{f} 2 \mathrm{f}$ lectures. Poor past performance, low self-efficacy, low task value, and high anxiety are also related to disorganised study strategies, low effort, and poor achievement (Bandalos et al., 2003). In traditional f2f courses, it is possible that these poor outcomes arise from avoidance of classes. Indeed, Billings-Gagliardi and Mazor (2007) reported that only $17 \%$ of first year medical students reported routinely attending all f $2 \mathrm{f}$ lectures. The other $83 \%$ made case-by-case costs-benefits decisions regarding attendance. Reasons given for not attending included the lecturer's approach, predicted outcomes of attending, the particular topic, and learning needs, as well as personal considerations such as the time of the lecture and other competing demands. Many of these factors are similar to those that predict choice of online over f $2 \mathrm{f}$ access (Copley, 2007). Providing asynchronous online access to lecture content via podcasts or lecture capture allows more convenient and flexible access to learning (Frydenberg, 2006; Nathan \& Chan, 2007), which addresses some of the practical reasons for not attending f2f lectures.

Asynchronous online access may also offer a less threatening means for some students to access the content in statistics courses. Social science students report high levels of anxiety about statistics and this is associated with avoidance and, subsequently, poor performance (Onwuegbuzie, 2003, 2004). In the current study, it was specifically fear of statistics teachers that predicted intentions to avoid f2f lectures and high class/test anxiety for statistics that predicted intentions to use lecture capture. Therefore, this suggests that students who are anxious about being in a statistics class and, in particular, facing statistics teachers, find the asynchronous online access less threatening. Similarly, interpretation anxiety predicted intentions to use the archived tutorials. Thus, those students who were particularly anxious about interpreting statistical equations and output, which is a major component of the work in tutorials, were more likely to prefer the asynchronous tutorial. General test anxiety and anxiety over seeking help in statistics were not significantly related to any of the intentions. Thus, this shows that it is specifically anxiety associated with being in a statistics class that is important rather than general anxiety about taking tests (the format of which were identical regardless of what format students accessed the lectures and tutorials in) or about seeking help with statistics. Therefore, it is important to use discipline specific measures when examining students' intentions.

In addition, a heavier reliance on rehearsal as a learning strategy was independently related to stronger intention to use lecture capture (and this predictor approached significance with intentions to use the archived tutorials as well). This is consistent with Huang et al. (2011) who found that students who preferred learning facts and using well-established methods for problem solving preferred online options. The fact that higher extrinsic motivation was also related to stronger intentions to use those asynchronous modes suggests that students driven to achieve and be seen to achieve perceive the accessibility and control afforded by asynchronous media as an important means to that end. Certainly ability to revise content is an advantage often reported for these media (e.g., Williams \& Fardon, 2007), and extrinsically motivated students may respond to that. However, intrinsic motivation, or the desire to learn and master content without considering external rewards, was unrelated to intentions.

There did appear to be two underlying reasons for students intending to use the online options more. One, as discussed, was negative attitudes, high anxiety, a preference for learning using rehearsal, and extrinsic motivation. However, positive approaches to learning were also related to intentions to use these online options. Higher use of critical thinking was significantly related to intentions to use the online options. Thus, students who wish to think more critically and deeply about the material recognize the benefits of 
these media for increasing control over the manner in which one can process the material. In addition, three aspects of self-regulation (metacognitive, time and environment, and effort) were related to intentions to use different online modes. The lack of a set timetable for accessing this online material demands a higher level of self-regulation in order to be successful in learning this way. This is consistent with Matheos et al.'s (2005) finding that independent learners preferred online options.

Contrary to expectations, there was little evidence that practical or technological considerations affected student's intended choices. However, engaging in more work outside of university was related to stronger intentions to use lecture capture, but not a concomitant intention to avoid f $2 \mathrm{f}$ lectures. This suggests that those students with more outside commitments do not specifically intend to miss $\mathrm{f} 2 \mathrm{f}$ classes, but perhaps know it is more likely they will due to competing demands and that they will use lecture capture more for that reason. In contrast, family and caring commitments did not play a role. Most of this sample did not have caring responsibilities so that may be one reason this was not an important factor. However, most did have part-time work commitments. Distance to the campus was not a factor in choices in the current study, although Rose et al. (2000) had found that it predicted the decision to enrol in an online over a $\mathrm{f} 2 \mathrm{f}$ course. The degrees in which the current sample was enrolled are only offered in on-campus mode and so students all lived within a reasonable distance of the campus $(100 \mathrm{~km}$ or less, except for the one student who flew in). Where degrees are offered in online or on-campus modes, distance may be a more important factor in the choices made. The only technological consideration was that having the SPSS software predicted intentions to attend the virtual tutorials. This software was essential to the tutorial activities. Research (Matheos et al., 2005; Rose et al., 2000) that has previously found that technological factors relating to having computers and the Internet predict choices may be outdated. Most students in this study had computers and the Internet at home. Many probably also had the internet on mobile phones, iPads, and laptops.

One question that this study does not answer is whether intentions to use the online options represent avoidance strategies that are likely to result in poorer achievement or whether the online options assist engagement, processing, and subsequent achievement by reducing the threat felt in attending f $2 \mathrm{f}$ classes and increasing the control over processing material. Asynchronous online options allow learners more control over the pace of delivery of material (Copley, 2007; Robinson \& Hullinger, 2008; Williams \& Fardon, 2007). They can pause, rewind, or slow down delivery speed. This provides time to think critically and more deeply about the material. The additional control that learners have with asynchronous online learning is particularly likely to benefit those students with high anxiety and concomitant low selfefficacy. Anxiety interferes with learning because cognitive processing capacity is directed from the task (learning statistics) to the cognitive components of worry (Ashcraft \& Kirk, 2001; Hopko, Ashcraft, Gute, Ruggerio, \& Lewis, 1998). This affects focus and students attribute this to poor ability (Ashcraft \& Kirk, 2001), which subsequently reduces self-efficacy (Pajares, 2002). This, in turn, results in high anxiety in the future when faced with similar tasks (Zohar, 1998). Therefore, allowing students' choice in how they access course content may be especially useful to the teaching of statistics and other "scary" courses. The ability of students to control the pace of delivery with asynchronously delivered online material can also have benefits for instructors. It means that they can deliver $\mathrm{f} 2 \mathrm{f}$ material at a pace that better suits them in terms of the time available to cover necessary content, rather than having to slow the pace or repeat material several times to meet the processing needs of some of the students (Gedik, Kiraz, \& Ozden, 2013). Students who require a slower delivery or the opportunity to hear it several times can access the asynchronous online option. Obviously, instructors still need to provide means for students to ask questions, but this can be achieved for those accessing the online material via online forums or discussion groups (Gedik et al., 2013).

Increasingly, higher education is using online or blended learning approaches. The Bradley Review of Australian Higher Education (2008) identified "An accessible and sophisticated online learning environment" (p. 79) as a key aspect in the provision of a quality student experience. However, the current results, along with those of related studies (e.g., Tselios et al., 2011), indicate that understanding the cognitive strategies employed by individual students along with the values and expectancies they have for learning is essential to designing a blended learning structure that will engage them and enhance their learning experience. Providing a well-designed blended learning buffet from which students can choose their preferred means of access to different learning activities (e.g., lectures versus tutorials) has the potential to better engage students by providing a better match for their particular approach to learning. The results of this study can inform the development of a pre-course screening battery to measure student 
attitudes and motivations, which would provide students with guidance on what means of delivery is likely to better suit them (similar to the approach taken in Ohio State University's Program in Course Redesign, 2005).

The provision of a blended learning buffet need not be expensive or time consuming for institutions or staff. It can be as simple as in the current study of providing asynchronous or synchronous access online to lectures and tutorials that are provided f2f. The technology to deliver synchronous virtual classes (e.g., via Wimba, or Blackboard Collaborate [https:/www.blackboard.com/Platforms/Collaborate/Products/ Blackboard-Collaborate.aspx]) as well as to capture $\mathrm{f} 2 \mathrm{f}$ classes for asynchronous online access (e.g., via Lectopia or Echo360 [http://echo360.com/]) is readily available in many universities. With the increasing development of associated apps for smart phones (e.g., Blackboard Collaborate has released an app for Android phones), accessibility and flexibility for students is increasing. However, Gedik et al. (2013) identified that it is important to provide students with sufficient orientation and instructions in utilising the online delivery. Ensuring all students adequate access to staff and interaction with other students are important considerations as well; however, these same tools can be used for virtual consultation and discussion groups overcoming that problem. Where courses require access to course-specific software, as in the current study, provisions need to be made for student access to this at home if they were to choose the online delivery modes. A student-version of the SPSS software required in the current statistics course is available packaged with a number of relevant textbooks. Having this software was a factor in intentions to choose the online tutorials so this is an important consideration.

Future research needs to extend this work to examine these individual characteristics in relation to actual behaviour. Given the strong relationship between intentions and behaviours (Ajzen, 2002; Cheng, 2011), it is expected that the relationships would be similar. However, it would be useful to also examine whether the behavioural choices made regarding $\mathrm{f} 2 \mathrm{f}$ versus online access and individual differences interact in their effects on outcomes. For example, do students with high anxiety who choose the online option perform better because they feel more control over the content compared to those with high anxiety who choose to attend $\mathrm{f} 2 \mathrm{f}$ ? Alternatively, does this result in poorer performance because it represents an avoidance or procrastination strategy? Until more is understood about how student characteristics influence the choices they make and how they then interact with those choices to affect achievement, blended learning cannot be well implemented.

\section{References}

Ajzen, I. (2002). Perceived behavioral control, self-efficacy, locus of control, and the theory of planned behavior. Journal of Applied Social Psychology, 32, 665-683. Retrieved from http://dx.doi.org/10.1111/j.1559-1816.2002.tb00236.x

American Psychological Association. (2009). Publication manual of the American Psychological Association (6th ed.). Washington, DC: Author.

Artino, A. R. (2010). Online or face-to-face learning? Exploring the personal factors that predict students' choice of instructional format. Internet and Higher Education, 13, 272-276. Retrieved from http://dx.doi.org/10.1016/j.iheduc.2010.07.005

Ashcraft, M. H., \& Kirk, E. P. (2001). The relationships among working memory, math anxiety and performance. Journal of Experimental Psychology: General, 130, 224-237. Retrieved from http://dx.doi.org/10.1037//0096-3445.130.2.224

Baharun, N., \& Porter, A. (2009). Teaching statistics using a blended approach: Integrating technologybased resources. In Same places, different spaces. Proceedings ascilite Auckland 2009. Retrieved from http://www.ascilite.org.au/conferences/auckland09/procs/baharun.pdf

Baloglu, M. (2002). Psychometric properties of the statistics anxiety rating scale. Psychological Reports, 90, 315-325. Retrieved from http://dx.doi.org/10.2466/pr0.2002.90.1.315 
Bandalos, D. L., Finney, S. J., \& Geske, J. A. (2003). A model of statistics performance based on achievement goal theory. Journal of Educational Psychology, 95, 604-616. Retrieved from http://dx.doi.org/10.1037/0022-0663.95.3.604

Billings-Gagliardi, S., \& Mazor, K. M., (2007). Student decisions about lecture attendance: Do electronic course materials matter? Academic Medicine, 82(10 Suppl.), S73-S76. Retrieved from http://dx.doi.org/10.1097/ACM.0b013e31813e651e

Bleed, R. (2001). A hybrid campus for the new millennium. Educause Review, 36, 16-24. Retrieved from http://net.educause.edu/ir/library/pdf/ERM0110.pdf

Bradley, D. (2008). Review of Australian higher education: Final report. Retrieved from http://www.innovation.gov.au/HigherEducation/Documents/Review/PDF/Higher\%20Education\%20 Review_one\%20document_02.pdf

Chang, S., \& Tung, F. (2008). An empirical investigation of students' behavioural intentions to use the online learning course websites. British Journal of Educational Technology, 39, 71-83. Retrieved from http://dx.doi.org/10.1111/j.1467-8535.2007.00742.x

Chen, P. D., Lambert, A. D., \& Guidry, K. R. (2008). Engaging online learners: The impact of Web-based learning technology on college student engagement. Computers \& Education, 54, 1222-1232. Retrieved from http://dx.doi.org/10.1016/j.compedu.2009.11.008

Cheng, Y. (2011). Antecedents and consequences of e-learning acceptance. Information Systems Journal, 21, 269-299. Retrieved from http://dx.doi.org/10.1111/j.1365-2575.2010.00356.x

Cohen, J. (1988). Statistical power analysis for the behavioral sciencies. Hillsdale, NJ: Lawrence Erlbaum Associates.

Copley, J. (2007). Audio and video podcasts of lectures for campus-based students: Production and evaluation of student use. Innovations in Education and Teaching International, 44, 387-399. Retrieved from http://dx.doi.org/10.1080/14703290701602805

Cruise, R. J., \& Wilkins, E. M. (1980). STARS: Statistical anxiety rating scale. Berrien Springs, MI: Andrews University.

Davis, F. D., Bagozzi, R. P., \& Warshaw, P. R. (1989). User acceptance of computer technology: A comparison of two theoretical models. Management Science, 35, 982-1002. Retrieved from http://dx.doi.org/10.1287/mnsc.35.8.982

Eccles, J. (2005). Subjective task value and the Eccles et al. model of achievement-related choices. In A. J. Elliot \& C. S. Dweck (Eds.), Handbook of competence and motivation (pp. 105-121). New York, NY: Guilford Press.

Eccles, J. S., Adler, T. F., Futterman, R., Goff, S. B., Kaczala, C. M., Meece, J. L., \& Midgley, C. (1983). Expectancies, values, and academic behaviors. In J. T. Spence (Ed.), Achievement and achievement motivation (pp. 75-146). San Francisco, CA: W. H. Freeman.

Fishbein, M., \& Ajzen, I. (1975). Belief, attitude, intention, and behavior: An introduction to theory and research. Reading, MA: Addison-Wesley. Retrieved from http://people.umass.edu/aizen/f\&a1975.html

Frydenberg, M. (2006). Principles and pedagogy: The two P's of podcasting in the information technology classroom. In Proceedings of the Information Systems Education Conference 2006, 23, 10pp. Retrieved from http://proc.isecon.org/2006/3354/ISECON.2006.Frydenberg.pdf

Garrison, R., \& Vaughan, H. (2008). Blended learning in higher education: Framework, principles and guidelines. San Francisco, CA: Jossey-Bass. 
Gedik, N., Kiraz, E., \& Ozden, Y. (2013). Design of a blended learning environment: Considerations and implementation issues. Australasian Journal of Educational Technology, 29(1), 1-19. Retrieved from http://ascilite.org.au/ajet/submission/index.php/AJET/article/view/6/21

Hanna, D., Shevlin, M., \& Dempster, M. (2008). The structure of the statistics anxiety rating scale: A confirmatory factor analysis using UK psychology students. Personality and Individual Differences, 45, 68-74. Retrieved from http://dx.doi.org/10.1016/j.paid.2008.02.021

Hopko, D. R., Ashcraft, M. H., Gute, J., Ruggerio, K. J., \& Lewis, C. (1998). Mathematics anxiety and working memory: Support for the existence of a deficient inhibition mechanism. Journal of Anxiety Disorders, 12, 343-355.

Huang, E. Y., Lin, S. W., \& Huang, T. K. (2011). What type of learning style leads to online participation in the mixed-mode e-learning environment? A study of software usage instruction. Computers \& Education, 58, 338-349. Retrieved from http://dx.doi.org/10.1016/j.compedu.2011.08.003

Matheos, K., Daniel, K., McCalla, G. I. (2005). Dimensions for blended learning technology: Learners' perspectives. Journal of Learning Design, 1, 56-76. Retrieved from https://www.jld.edu.au/article/view/9/6

Means, B., Toyama, Y., Murphy, R., Bakia, M., \& Jones, K. (2010). Evaluation of evidence-based practices in online learning: A meta-analysis and review of online learning studies. Retrieved from http://www2.ed.gov/rschstat/eval/tech/evidence-based-practices/finalreport.pdf

Nathan, P., \& Chan, A. (2007). Engaging undergraduates with podcasting in a business subject. In ICT: Providing choices for learners and learning. Proceedings ascilite Singapore 2007. Retrieved from http://www.ascilite.org.au/conferences/singapore07/procs/nathan.pdf

Neumann, D. L., \& Hood, M. (2009). The effects of using a wiki on student engagement and learning of report writing skills in a university statistics course. Australasian Journal of Educational Technology, 25(3), 382-398. Retrieved from http:/www.ascilite.org.au/ajet/ajet25/neumann.html

Neumann, D. L., Neumann, M. M., \& Hood, M. (2011). Evaluating computer-based simulations, multimedia, and animations that help integrate blended learning with lectures in first year statistics. Australasian Journal of Educational Technology, 27(2), 274-289. Retrieved from http://www.ascilite.org.au/ajet/ajet27/neumann.html

Onwuegbuzie, A. J. (2003). Modeling statistics achievement among graduate students. Educational and Psychological Measurement, 63, 1020-1038. Retrieved from http://dx.doi.org/10.1177/0013164402250989

Onwuegbuzie, A. J. (2004). Academic procrastination and statistics anxiety. Assessment and Evaluation in Higher Education, 29, 1-19. Retrieved from http://dx.doi.org/10.1080/0260293042000160384

Pajares, F. (2002). Overview of social cognitive theory and of self-efficacy. Retrieved from http://p20motivationlab.org/social-cognitive-theory

Palmgreen, P. (1984). Uses and gratifications: A theoretical perspective. In R. N. Bostrom (Ed.), Communication Yearbook 8, (pp. 61-72). Beverly Hills, CA: Sage Publications.

Picciano, A. G. (2009). Blending with purpose: The multimodal model. Journal of the Research Center for Educational Technology, 5, 4-14. Retrieved from http://www.rcetj.org/index.php/rcetj/article/download/11/14 
Pintrich, P. R., Smith, D. A. F., Garcia, T., \& McKeachie, W. J. (1991). A manual for the use of the motivated strategies for learning questionnaire (MSLQ). Ann Arbour, MI: National Institute for Research to Improve Postsecondary Teaching and Learning. Retrieved from http:/www.scribd.com/doc/93744041/Motivated-Strategies-for-Learning-Questionnaire-Manual

Program in Course Redesign (2005). The Ohio State University. Retrieved from http://www.thencat.org/PCR/R3/OSU/OSU_Overview.htm

Robinson, C. C., \& Hullinger, H. (2008). New benchmarks in higher education: Student engagement in online learning. Journal of Education for Business, 84, 101-108. Retrieved from http://dx.doi.org/10.3200/JOEB.84.2.101-109

Rose, M., Frisby, A., Hamlin, M., \& Jones, S. (2000). Evaluation of the effectiveness of a web-based graduate epidemiology course. Computers in Nursing, 18, 162-167.

Schober, B., Wagner, P., Reimann, R., Atria, M., \& Spiel, C. (2006). Teaching research methods in an internet-based blended-learning setting: Vienna e-lecturing (VEL). Methodology, 2, 73-82. Retrieved from http://dx.doi.org/10.1027/1614-1881.2.2.73

Tselios, N., Daskalakis, S., \& Papadopoulou, M. (2011). Assessing the acceptance of a blended learning university course. Educational Technology \& Society, 14, 224-235. Retrieved from http://www.ifets.info/journals/14_2/19.pdf

Tudor, G. E. (2006). Teaching introductory statistics online - Satisfying the students. Journal of Statistics Education, 14(3). Retrieved from http://www.amstat.org/publications/jse/v14n3/tudor.html

Twigg, C. A. (2003). Improving learning and reducing costs: Models for online learning. Educause Review, 38, 28-38. Retrieved from http://net.educause.edu/ir/library/pdf/erm0352.pdf

Utts, J., Sommer, B., Acredolo, C., Maher, M. W., \& Matthews, H. R. (2003). A study comparing traditional and hybrid internet-based instruction in introductory statistics classes. Journal of Statistics Education, 11(3). Retrieved from http://www.amstat.org/publications/jse/v11n3/utts.html

Ward, B. (2004). The best of both worlds: A hybrid statistics course. Journal of Statistics Education, 12(3). Retrieved from http://www.amstat.org/publications/jse/v12n3/ward.html

Williams, J., \& Fardon, M. (2007). Perpetual connectivity: Lecture recordings and portable media players. In ICT: Providing choices for learners and learning. Proceedings ascilite Singapore 2007. Retrieved from http://www.ascilite.org.au/conferences/singapore07/procs/williams-jo.pdf

Yablon, Y. B., \& Katz, Y. J. (2001). Statistics through the medium of internet: What students think and achieve. Academic Exchange Quarterly, 5, 17-22.

Zohar, D. (1998). An additive model of test anxiety. Journal of Educational Psychology, 90, 330-340. Retrieved from http://dx.doi.org/10.1037/0022-0663.90.2.330

Corresponding author: Michelle Hood,michelle.hood@griffith.edu.au

Australasian Journal of Educational Technology (C) 2013.

Please cite as: Hood, M. (2013). Bricks or clicks? Predicting student intentions in a blended learning buffet. Australasian Journal of Educational Technology, 29(6), 762-776. 